\title{
Health care financing in China prior to health reform 2009
}

\author{
Khatri JR1, Shuiyuan $\mathrm{X}^{2}$ \\ School of Public Health, Central South University, Changsha, Hunan, China
}

1Student, Social Medicine and Health Management (2008-2011), School of Public Health, Central South University, China. ${ }^{2}$ Dean, School of Public Health, Central South University, Changsha, Hunan, China

\begin{abstract}
Background and Objectives: The health system of China in 1970 was an exemplary model to the world but it began deteriorating after the economic reform in 1980. In order to address the deteriorating health system, government of China implemented the ambitious health reform program in 2009, with the aim to provide "safe, effective, convenient and affordable" health service to all people by 2020. In this study we try gain more insight about the health financing system of China prior to health system reform 2009.

Methodology: Secondary data were collected from online data sets of World Health Organization (WHO), World Bank, Economic Co-operation and Development (OECD) and from publicly available reports and documents of related Ministries, and other published sources. Analysis was done with descriptive approach, focused on the three dimensions of health, namely the financing system: total health expenditure, financing source and financing scheme/agents.

Results: China's total health expenditure (THE) from 1995 to 2008 remained below 5\% of GDP. From 1995 to 2001, the Government share on health expenditure decreased continuously and reached the lowest level of $36.4 \%$ in 2001. Private financing was the primary funding mechanism and sources of revenue for private financing were private insurance and out-of-pocket payments. Household spending on health has increased with an average growth rate of $11.5 \%$ from 2000 to 2008. Health financing scheme was social insurance type with fragmented risk pooling.

Conclusions: Low level of public funding and heavy reliance on out-of-pocket payment were the major problem in the past decades. Hence the daunting problem of inadequate health financing ruled the last three decade of China health system.
\end{abstract}

Key words: China, Health Financing, Health System, Reform

\section{INTRODUCTION}

In 1970, China depicted a role model of health system with its superior health system performance to the world [1]. Almost universal access to the quality health care was being provided for the entire population; as a consequence, remarkable health 
performance could be observed [2]. The majority of the people, including both rural and urban, were covered by one of the "health insurance scheme", i.e. government insurance scheme (GIS), labor insurance scheme (LIS) or cooperative medical scheme (CMS) [3]. The shining example of health development started to fade and just became history after the economic reform in 1980 .Central government started to decrease its influential role from health care leading to an increase in the role of private sector. Rapid reduction in the share of the government health expenditure as a proportion of total health expenditure from $40 \%$ to $18 \%$, more than half, in between 1980 and 2005 [4], and privatization of the health institution were some examples of the decrease in government role [5]. Similarly, health insurance coverage was highly affected especially in the rural areas, where about $80 \%$ of the workers lacked health insurance in 2003[6] and an increase in financial burden along with the rise in out-of-pocket payment for health service from $20 \%$ to more than 50\% between 1980 and 2005 was estimated [4].

In order to address continually rising health care costs, inadequate resources' allocation to health service, inadequate health insurance coverage, health disparities and health equity, the government of China announced health system reform plan for the next decade in 2009. With the aim to provide "safe, effective, convenient, and affordable" health services to all people by 2020, the government has launched an ambitious three-year 850 billion Yuan RMB action plan, which was implemented in 2009 [7]. The government, in accordance with this three-year plan, aims to include of $90 \%$ of population under Primary medical insurance (Urban employees' basic medical insurance scheme (UEBMI), The urban residents' basic medical insurance (URBMI) and New Rural Cooperative Medical Scheme (NRCMS) and to finance the development of health care centers and hospitals in rural town and county, and also community health centers in less developed urban areas. This plan also includes the increase in hospitalized expense imbursement rate under UEBMI, URBMI and NRCMS, up to $75 \%, 60 \%$ and $50 \%$ respectively and the increase in average wages [8-10]. Studies suggest that in the past three decades, along with the problem of health disparities and inequity in resource distribution, China's health system also faces the problems of inadequate heath funding, cost escalation and high personal health expenditure [11]. Health financing always remains the core component of any health system and is fundamental to the ability of health system to maintain and improve human welfare [12].

In this article we try to explore the health expenditure and health financing of China and gain more insight about how the health care financed in China prior to health system reform; what the trends in health expenditure were, what the major source of health funding were, how revenue was generated, what trends in health financing were and how the population was protected from financial risk. Also, we made a specific comparison of health financing and health outcomes with economically stronger country U.S.A, to understand the performance of health system and the level of health expenditure and health financing in China.

\section{MATERIALS AND METHODS}

Data used in this study are secondary type. The fundamental sources of data are online data sets of different national and 
international agencies depending on the quality and availability of data. Most of the data were derived from online data sets of World Health Organization (WHO), World Bank, Economic Co-operation and Development (OECD), Statistical Yearbook, publicly available reports and documents of related Ministries, and other published sources.

Data for the study of health expenditure and health financing were derived from National Health Account published by WHO. Data for the health insurance were derived from the publicly available published sources like report of national survey published by Ministry of Health and from other related literature. For demographic and socioeconomic purposes, the online source of World Bank, OECD, and Statistical year book were used. Data from World Health Statistics published by WHO, were used for the health outcome measure. Also other related published reports and documents were used, wherever required. No change in data has been made and because some limitation data were not subjected to verification, we completely relied on the sources for quality of data and methodology of the data collection.

Analysis was done with descriptive approach, focused on the three dimensions of health, namely the financing system: total health expenditure, financing source and financing scheme/agents. We categorized the financing source into public and private and used the available published data for analysis. Financial scheme/agent was also categorized into social health insurance, risk pooling and coverage. Under social health insurance we focused on the available three social health insurance of China (UEBMI, URBMI and NRCMS). In contrast to the financial source, analytical descriptions of financial scheme/ agent were made on the basis of literature review. Simple mathematical calculations were performed to obtain growth rate and percentage of different values, but no significance tests were performed. Since we relied on secondary sources, our analyses have been rearranged and we have tried to compile what is already known about health financing in China. From our analysis, we hope to provide an in-depth knowledge of health financing system of China.

\section{RESULTS}

Level of health expenditure: China's total health expenditure (THE) in 2008 was estimated to be 1,317,074 million Yuan RMB, which was about $4.3 \%$ of gross domestic product GDP (Table 1). This share has increased from 3.5\% in 1995 but throughout the period it remained below $5 \%$ of GDP.

However in real value there has been an increase by more than 6 fold in health expenditure from 212,659 million Yuan (3.5\% of GDP,1995) to $1,317,074$ million Yuan $(4.3 \%$ of GDP,2008). This increasing trend can also be observed in the growth of real per capita health spending. Per capita health expenditure in 1995 was about 21 \$, which reached $142 \$$ in 2008 indicating the increase of about 7 fold.

According to figure 1, in 2001, the growth rate of health care expenditure (THE) (8.2\%) and growth rate of GDP (8.3\%) was similar. Although, growth of both GDP and health care expenditure has increased in almost all the years between 2001 and 2008, health care expenditure attained the faster growth than GDP. As the Health care expenditure showed higher increase in 2002, its growth rate has 
Table 1: Health Expenditure, its growth rates and Trend

\begin{tabular}{|c|c|c|c|c|c|c|c|c|c|c|}
\hline Indicators & Year & 2000 & 2001 & 2002 & 2003 & 2004 & 2005 & 2006 & 2007 & 2008 \\
\hline \multirow[t]{3}{*}{$\begin{array}{l}\text { Health } \\
\text { Expenditure } \\
\text { (Million Yuan } \\
\text { RMB) * }\end{array}$} & THE (a) & 453,612 & 491,205 & 559,744 & 636,650 & 726,467 & 822,467 & 927,642 & $1,096,679$ & $1,317,074$ \\
\hline & GGHE(b) & 175,591 & 178,780 & 207,478 & 238,514 & 288,230 & 335,713 & 400,170 & 490,679 & 615,328 \\
\hline & PvtHE(c) & 278,021 & 312,425 & 352,256 & 398,136 & 438,237 & 486,754 & 527,472 & 606,000 & 701,746 \\
\hline $\begin{array}{l}\text { Per capita THE } \\
\text { (average } \\
\text { exchange rate } \\
\text { US\$)* }\end{array}$ & (d) & 43 & 46 & 53 & 59 & 67 & 76 & 88 & 108 & 142 \\
\hline \multirow[t]{4}{*}{ Growth rate } & $\mathrm{a}$ & & 8.29 & 13.95 & 13.74 & 14.11 & 13.21 & 12.79 & 18.22 & 20.10 \\
\hline & $\mathrm{b}$ & & 1.82 & 16.05 & 14.96 & 20.84 & 16.47 & 19.20 & 22.62 & 25.40 \\
\hline & c & & 12.37 & 12.75 & 13.02 & 10.07 & 11.07 & 8.37 & 14.89 & 15.80 \\
\hline & d & & 6.98 & 15.22 & 11.32 & 13.56 & 13.43 & 15.79 & 22.73 & 31.48 \\
\hline $\begin{array}{l}\text { GDP growth } \\
\text { rate * }\end{array}$ & & 8.4 & 8.3 & 9.1 & 10 & 10.1 & 11.3 & 12.7 & 14.2 & 9.6 \\
\hline $\begin{array}{l}\text { Percent share } \\
\text { of GDP }\end{array}$ & a & 4.57 & 4.48 & 4.65 & 4.69 & 4.54 & 4.49 & 4.40 & 4.26 & 4.34 \\
\hline & $\mathrm{b}$ & 1.77 & 1.63 & 1.72 & 1.76 & 1.80 & 1.83 & 1.90 & 1.90 & 2.03 \\
\hline & c & 2.80 & 2.85 & 2.93 & 2.93 & 2.74 & 2.66 & 2.50 & 2.36 & 2.31 \\
\hline
\end{tabular}

*Source: WHO (2011) National Health Account, OECD.

\section{Figure 1: Trend in Growth Rates of different variables}

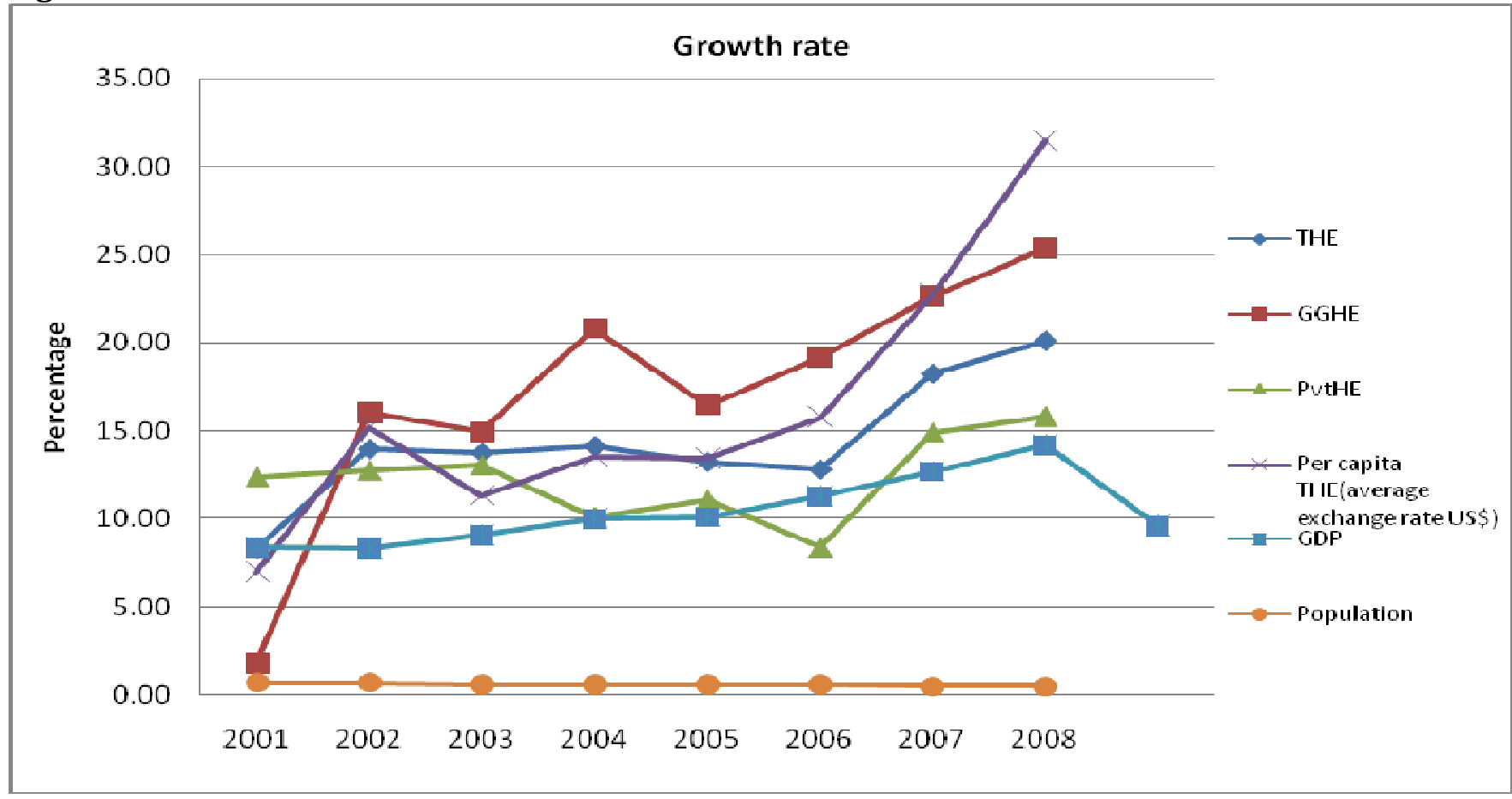

touched the mark of nearly $14 \%$, which led to 
larger gap between GDP and the growth rate. Continuous increase in growth rate of GDP and slowing down in health spending rate led to similar growth rate in 2006 . Then after, the gap between them has widened because of the faster increase in the growth rate of the health care expenditure and slowing down in the GDP growth rate. In 2008, the GDP growth rate reached $9.6 \%$, the growth rate achieved an increase of $20 \%$ compared to the previous year. Similarly, the decline in the population growth rate and incline in growth rate led to the increase in per capita total health spending on health. With the increase in the gross domestic product, health sector also experienced the higher growth rate in terms of total health spending. However the share of THE in terms of GDP did not increase, indicating lower government concern over the health care.

Health source financing in china: Figure 2 explains the contribution of different funding sources towards health expenditure. Low spending in health care was also exacerbated by low public investment and high private share. Public sector and Private sector were two major sources for funding the health care in China. Private health expenditure (PvtHE) constituted the largest source for health financing, bearing about $54 \%$ (2008) of the total health expenditure, which is $6.5 \%$ higher than the public expenditure on health care.

In 1995, general government had spent about $52 \%$ of the total health spending and the difference between the government health spending and private health spending was about 3\%. Since 1995, the Government share on health expenditure decreased continuously and reached the lowest level of $36.4 \%$ in 2001, in the contrary, the share of private expenditure had inclined to the peak of $63.6 \%$, leading to a difference of $27 \%$ between government and private spending, which affirms the important role played by private sector in health care. From 2001, government health spending increased continuously but the share still remained

\section{Figure 2: Trend in Distribution of Different Health Financing Sources}

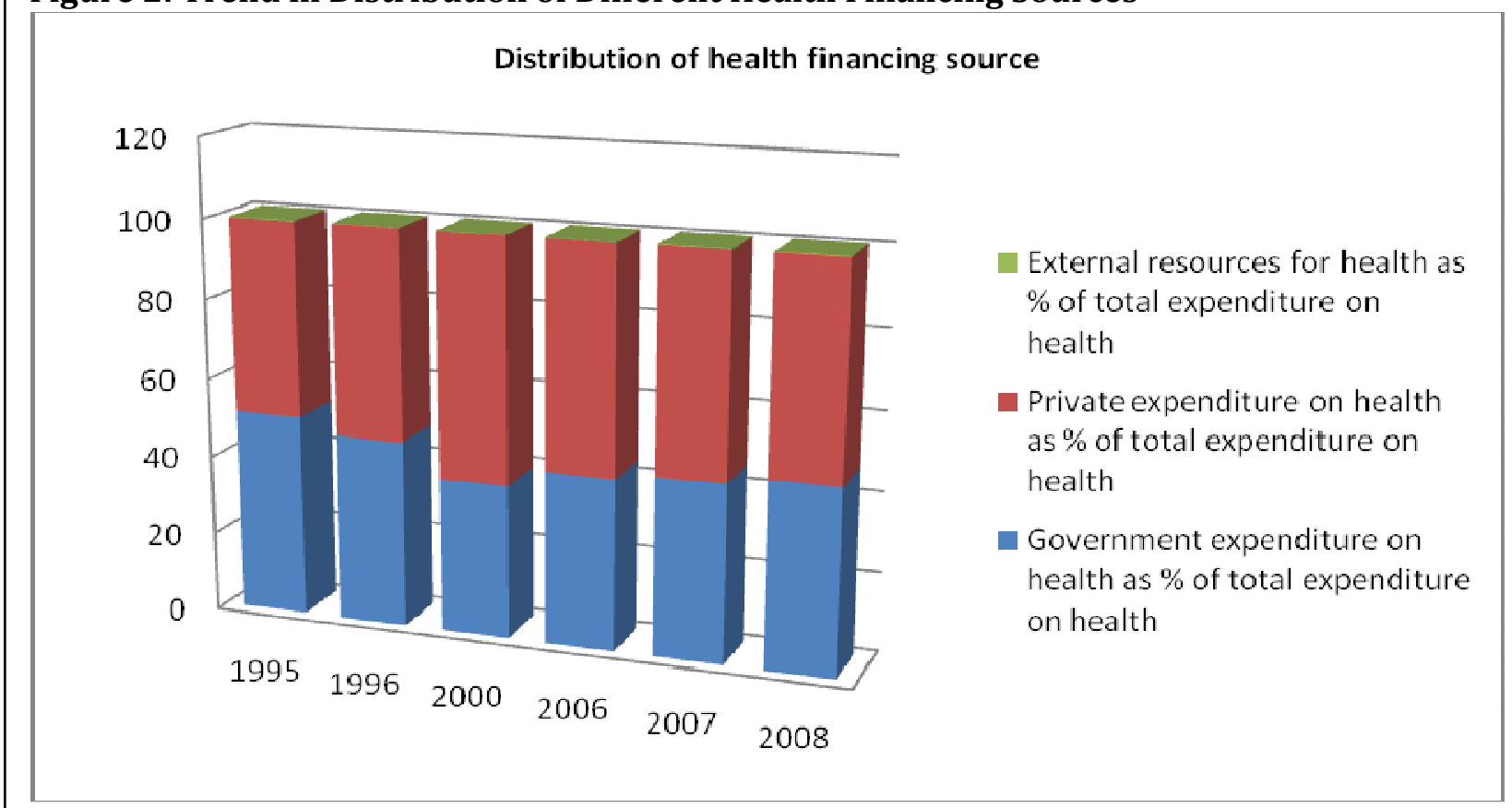


lower than that of 1995. The share contributed by the external resources accounts for only $0.2 \%$ of all expenditure on health in 2008.

Public Financing: Public expenditure or government funding allocated to the health sector in 2008 was 615,328 million Yuan RMB, which comprised only about $2 \%$ of the GDP and $10 \%$ of the total expenses made by the general government. This amount was 5 fold greater than the amount government had allocated in the year 1995. Out of total health expenditure, public expenditure shared about $47 \%$ in 2008, 5\% lower than 1995 and 10\% higher than the 2001. Public financing on health as a proportion of GDP had shown an increase from $1.7 \%$ (1995) to $2.03 \%$ ( 2008) (Figure 3). This increase did not reflect the higher share of public spending on health care, as the difference between total health expenditure and general government expenditure, as proportion of GDP, had increased over same period. In 1995 the difference was less than $2 \%$ which in 2008 increased to more than $2.5 \%$. This was also supported by less government spending on health care compared to total government expense. The share of government expense on health care as a proportion of total government expense was high during 19951996 (16\%) which later decreased and remained less than $10 \%$ of total expense in 2008. Low public spending was further supported by lower per person government expenditure on health and growing difference between per person total health expenditure to per person government spending on health.

From 1995 to 2008 there was an increment in per person government spending on health as well as the per person total health expenditure. The growth of the per person total health expenditure was faster than per person government expenditure on health, which resulted in huge difference of 76 US\$ (2008) per person. This difference was greater than what government had spent per person by US10\$ in 2008, and 7 fold higher than the difference in 1995. Increase in total health expenditure of a person with government having lower share per person added the higher burden for the individual expenditure on health.

Generally, Most of the revenue for the public spending comes from tax revenue through budget and contribution to social security fund. In China, social security funds continue

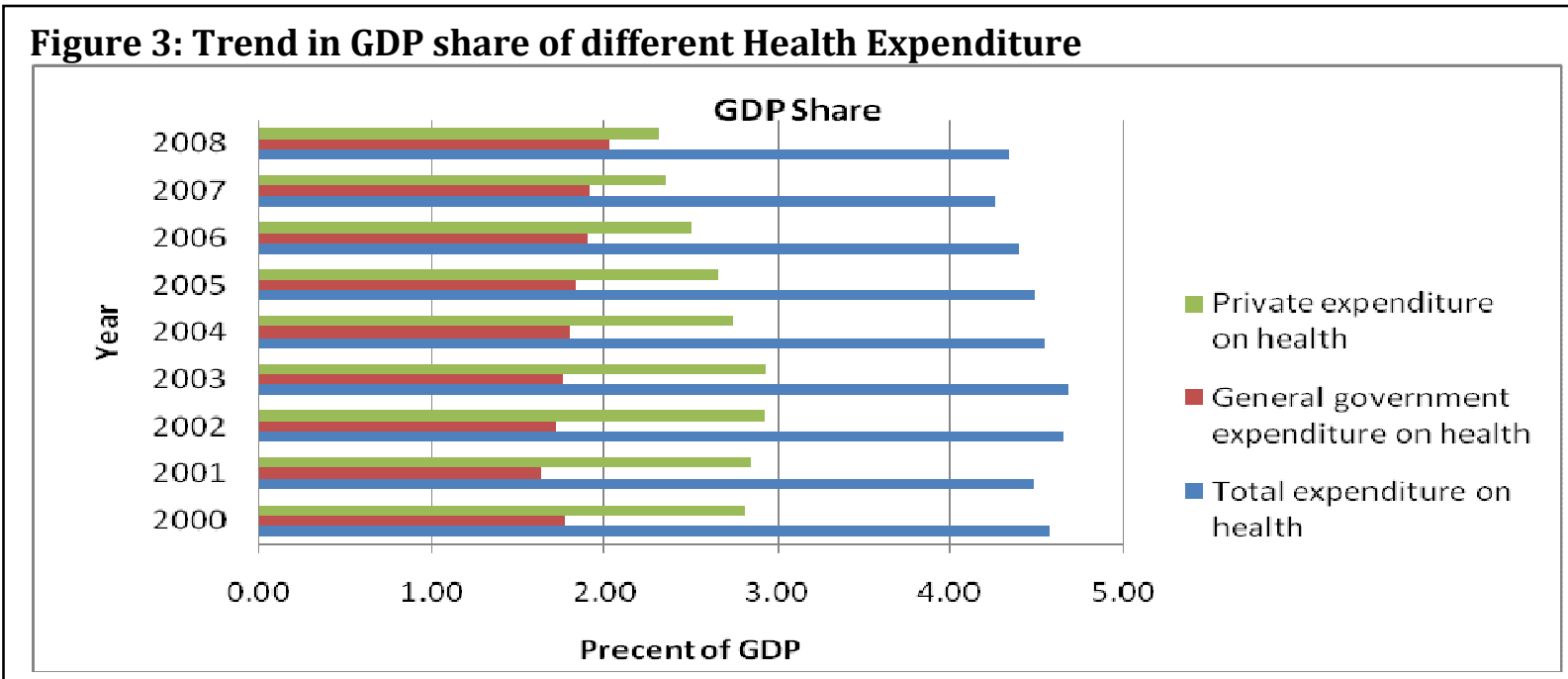


to be the largest source for public spending. More than half of the general government revenue for health expenditure arises from the social security financing. Basic medical insurance scheme for urban employees, basic medical insurance for urban residents, new rural cooperative medical scheme and medical assistance program were the financing system responsible for the major contribution on social security fund. In 2007 2008 , about $55 \%$ of the general government health expenditure (GGHE) was funded from the social security, which in 1995 was $65 \%$ and in 2002-2003 was 54\%. Although the percentage contribution of social security towards GGHE decreased, the absolute volume of social security contribution continued to increase. In 2008, out of 615,328 million Yuan RMB allocated by the government for health spending, the social security fund shared about 340,094 million Yuan RMB which in turn was 25\% more than the previous year 271,200 million Yuan RMB (2007) and about 5 fold greater than that of 1995. Also local government was more responsible for the public health than the central government, as local and central government sectors accounted for $90 \%$ and $10 \%$ of health spending funded through general government in 2006 respectively [13].

Private Financing: As from table 1 and figure 2 , private financing was the primary funding mechanism for China health system. High contribution of private expenditure compared to public on total health expenditure highlight the increasing role of private sector on healthcare. Private health care expenditure amounted to 701,746 million yuan in 2008, which was about $54 \%$ of total health expenditure and $2.3 \%$ of the GDP. Private expenditure on health care has incresaed by 7 fold compared to 103,823 million yuan RMB in 1995. Over the same period its share on total health expenditure had increased from $48.8 \%$ in 1995 to achieve the highest level of $64 \%$ in 2001 and decreased since then. Although the growth rate of private expenditure seemed to be slower than the public expenditure but its share to total health expenditure was still high. Decrease in growth rate of private financing was also supported by the decrease

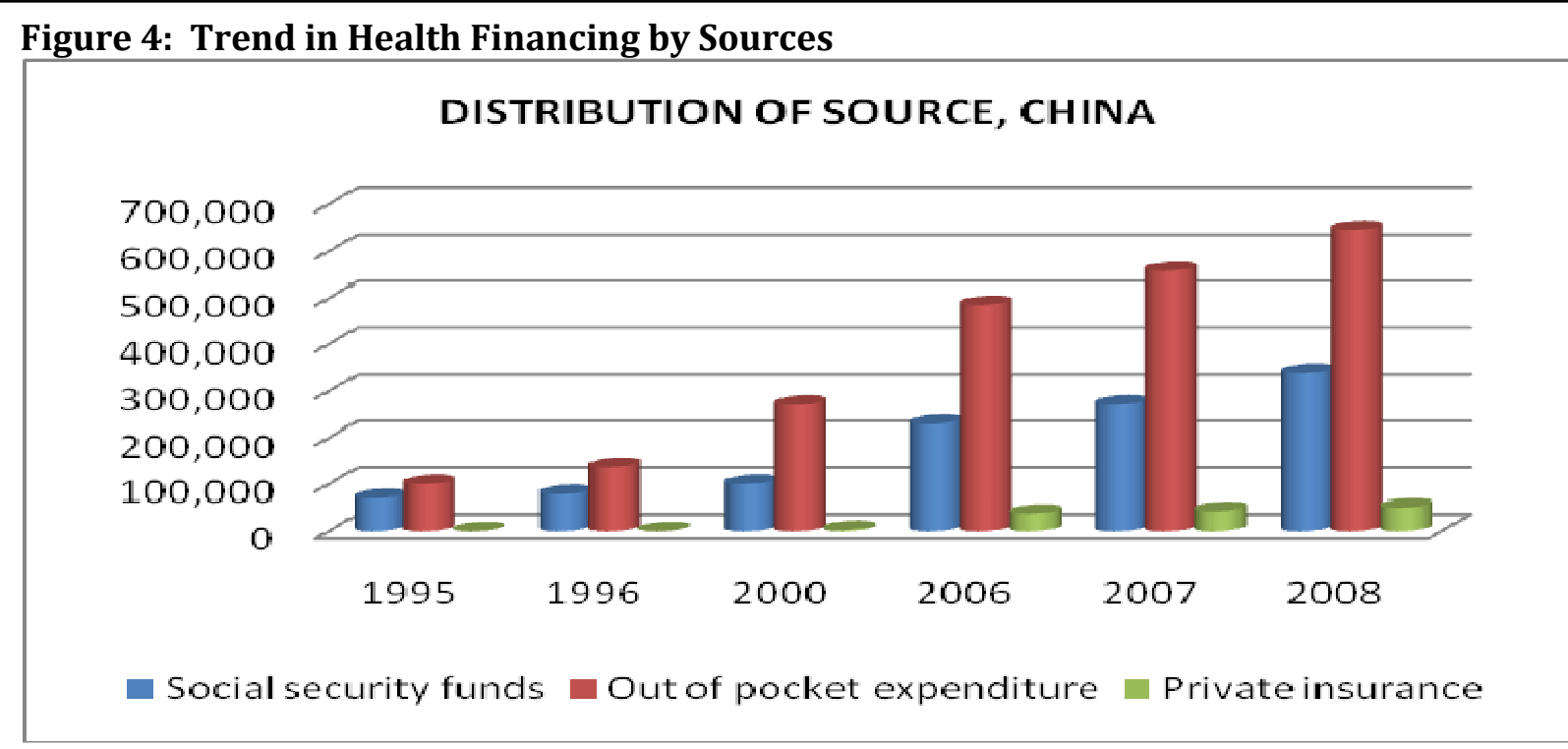


in its share to GDP (from figure 3). For e.g in 2002-2003 its share to GDP was 2.93\% which in 2008 decreased to $2.31 \%$. whereby in the same period total health expenditure also decreased but slight increase in government health expenditure can be observed.

Essentially, the sources of revenue for private financing were private insurance and out-ofpocket payments, as from Figure 4.

In China, out-of-pocket expenditure alone accounted for $92 \%$ of total private expenditure or about 645,715 million Yuan RMB was paid on health care as out of pocket in 2008 , which was around $50 \%$ of the total health expenditure. For the last 8 years, household' spending on health has increased with an average growth rate of $11.5 \%$, observing two trends on its growth. From 2001 to 2006, there was a decrease in the growth rate from $11.4 \%$ to $7.3 \%$ then started to accelerate to attain the growth rate of nearly $16 \%$ in 2008. Also, its share on total GDP had increased from 1.6\% in 1995 to $2.13 \%$ in 2008 . Unlike the growth rate and share to GDP, Out-of pocket payments contribution towards total health expenditure has dropped continuously from 61\% in 2001 to $49 \%$ in 2008 . Although private insurance exists, its coverage is very low and limited and people had to rely on their own source of finance in order to meet the cost of their health care. Only about 50,156 million Yuan RMB was financed from private insurance in 2008 , which is about $7 \%$ of total private expenditure on health and $3 \%$ of total health expenditure. Financing on health care by Private Insurance has been growing slowly and steadily. For e.g. in 2001 private insurance accounts only $1 \%$ of private expenditure on health, and this value has increased by $6 \%$ over 8 years.
Financing agents / schemes (HF): With the aim to provide accessible and affordable health service universally, government of China has announced ambitious reform programs to be carried out from 2009 to 2011 [14]. Government, under the three years plan, aims to achieve: Coverage of $90 \%$ of population under primary medical insurance, finance for the development of health care centre's and hospitals in rural towns and counties, and community health centre's in less developed urban areas [8-10].

Health financing scheme in China was social insurance type, whose policy-making and development was jointly governed by the Ministry of Health and the Ministry of Labor and Social Security, with significant local flexibility [15].

Social insurance for urban and rural population includes three major schemes (Table 2):

(1) Urban employees' basic medical insurance scheme (UEBMI) :It was established in 1998 by the Chinese state council and is employment- based medical insurance scheme for urban workers. Participation is mandatory for the employees of both public and private companies [16]. Payroll taxes paid by employer and employees are the source for funding, in which employers and employees share $6 \%$ and $2 \%$ of the total wages/ salary respectively. This scheme consists of 2 kinds of funds managed by local governments. First one is general medical trust fund, a pooled fund for inpatient stay, which consists of $70 \%$ of employer's contribution. Next is individual medical saving account for outpatient service, $70 \%$ of employer's contribution goes to this fund. Eligible retirees of bankrupted or closed down enterprises are also covered by this 


\section{Table 2: Financing scheme/agent, China}

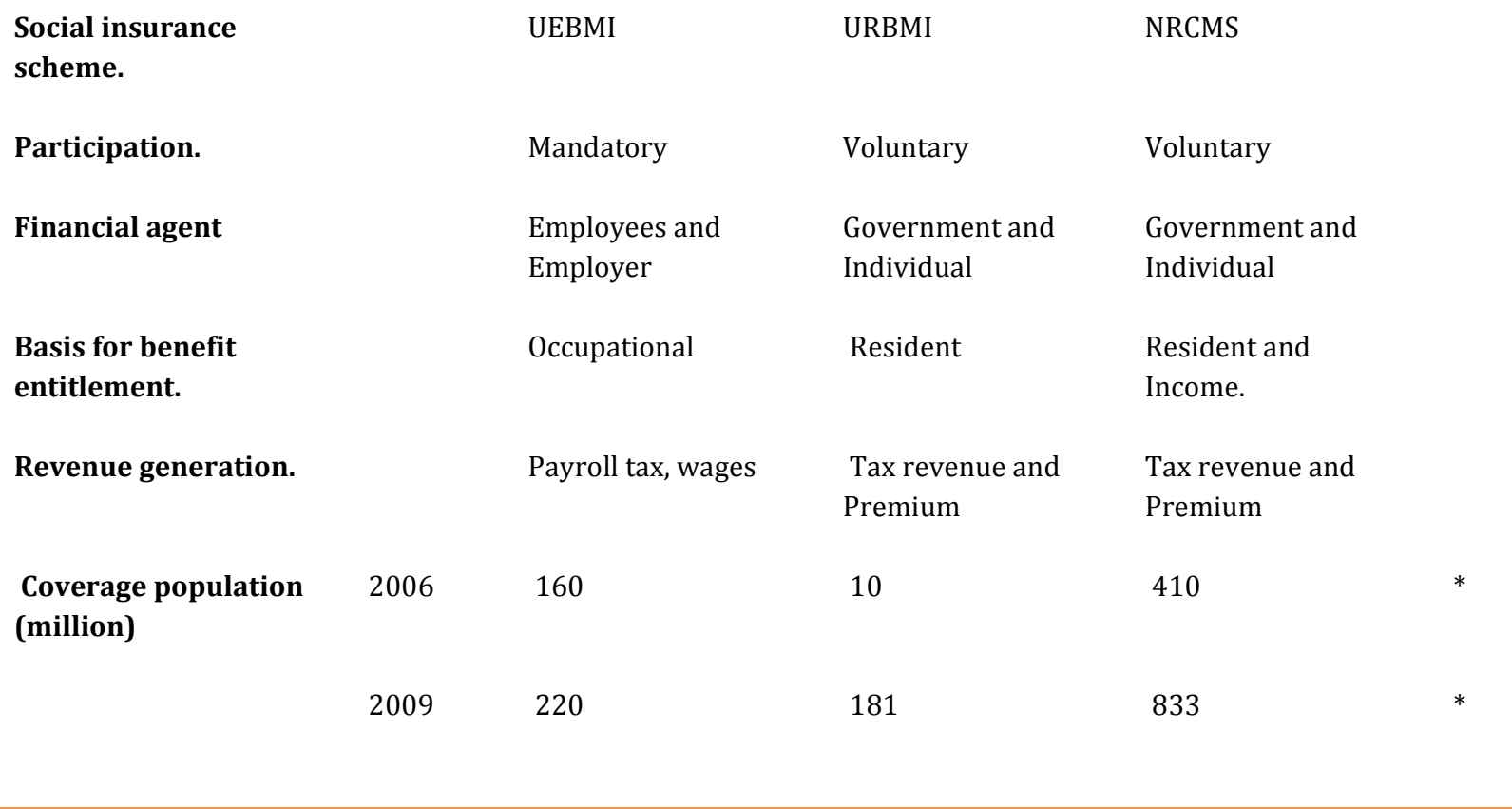

* Source: China's health reform; Health International 2010 No 10.

scheme for which subsidies are given by the central government.

(2) The urban residents' basic medical insurance (URBMI): Under this scheme, urban residents who are not covered by UEBMI such as children, student, unemployed urban resident, disabled etc are eligible for the enrollment. It is voluntary type, which was started in 2007, and eligible candidates have to contribute a certain amount for membership. Financing comes from central government with equal contribution from the local government [16].

(3) New Rural Cooperative Medical Scheme (NRCMS): This scheme provides the insurance coverage for the rural resident and was started in 2003. Mode of participation is voluntary for which rural resident have to make the specific contribution. Similar to URBMI, central government and local government provide equal amount of subsidies for the each membership [17]. In 2010, per person premium was $150 \mathrm{CNY}$, jointly, central government and local government covered $80 \%$ of the premium whereas rest is met by the participants [18].

Government has improved the subsidy and benefit level of URBMI and NRCMS, increasing the total contribution from government to 120 Yuan per person per annum along with increase in individual premium [14].

Also, urban and rural poor people who are receiving the minimum living standard allowance are further assisted by the medical financial assistance (MFA) program which began in 2003. Its acts as an important source for the poor people to pay NRCMS premiums and co-payments [18] and financed mutually by central government and local government [19]. 
Fee-for-service is the most common payment method for physicians, although some provinces use a mix of salary, capitation and free-for-service.

Risk Pooling: National level and provisional level medical insurance fund for the risk pooling does not exist in China [20]. Social insurance system of China features fragmented risk pooling [21]. Individuals are assigned to different financial scheme depending upon their geographical location and employment state, and the responsibility of the authorities for managing insurance fund also differs along with source of financing and enrollment method.

UEBMI and URBMI have the different source of financing one by the employee and employers with mandatory participation, the other by individual and government with voluntary participation. Both are urban based, and consists of medical insurances fund- a pooled insurance fund managed independently by same insurance agent, where the amount contributed for participation is deposited and later used as payment for health service depending upon expenditure. In each administrative region, municipal and county medical insurance bureaus are responsible for managing these funds at local level and for UEBMI provincial medical insurance bureaus area are also responsible for insurance fund for employees and retirees of all government agencies.

On the other hand NRCMS is rural based scheme, where the enrollment is voluntary for family and governments as well as the participants are the source of financing. Risk pooling is at county level and consists of pooled insurance account where all subsidies and revenue collected is deposited. County government and departments of health are responsible for financing, enrollment and managing all payments for the health service coverage in their respective location.

Coverage of social insurance: All together in 2009, the rural and urban basic medical insurance scheme covers more than 1.2 billion people, out of which about 400.61 million people were enrolled in urban basic medical insurance scheme [22, 23].

In 2008, social insurance scheme gain the coverage of $87 \%$ of total population, where NRCMS has the share of $68 \%$, UEBMI $15 \%$ and URBMI $4 \%$ of total population [14, 18]. Higher proportion of the rural population, about $90 \%$ was covered by the insurance scheme compared to $65 \%$ of urban population in 2008 [18]. NRCMS also experienced the rapid expansion in coverage. Rural resident enrolled to NRCMS have increased from $3 \%$ in 2004 to $40.57 \%$ in 2006 and in 2009 its covers about 833 million rural resident $[17,18]$. Also the numbers of counties have increased to 2451 in 2007, from 310 in 2004 [17]. Rapid increase in the coverage of NRCMS is the major contribution for the growth of total coverage [18].

\section{DIFFERENTIALS AND SIMILARITIES WITH U.S.A}

China has the world's largest population and the highest GDP growth rate, and U.S.A has the world's most expensive health system. In recent years, both U.S.A and China have introduced health system reform. Health insurance coverage has become the highly focused area for both countries' program. Similar problems in two countries in the past years were access to health care, high cost of health service, quality care and disparities. 
Table 3: China and U.S.A National Expenditure on Health

Selected indicators/YEAR

USA

CHINA

2000

2008

2000

2008

Population (in thousands)

282,194

$1,266,954 \quad 1,337,411$

304,545

Total expenditure on health as \% of gross

domestic product

13.4

16

4.6

4.3

Government expenditure on health as \% of total expenditure on health

43.2

46.5

38.7

46.7

Private expenditure on health as $\%$ of total expenditure on health

56.8

53.5

61.3

53.3

Government expenditure on health as \% of

total government expenditure

17.1

19.2

11.1

9.9

External resources for health as \% of total

expenditure on health

$0 \quad 0$

0.1

Social security expenditure on health as \% of

general government expenditure on health

33.5

27.2

57.2

55.3

Out of pocket expenditure as $\%$ of private

expenditure on health

25.5

22.6

97.3

92

Private prepaid plans as $\%$ of private

expenditure on health

60.3

63.8

1

7.1

Per capita total expenditure on health (PPP int.\$)

$\begin{array}{lll}4,703 \quad 7,536 & 108\end{array}$

Per capita government expenditure on health

(PPP int.\$)

$2,032 \quad 3,506$

42

121

Sources: National Health Account 2011, WHO; World Population data sheet 2010, PRB 
China varies widely with U.S.A when it comes to comparing the health care expenditure and financing (Table 3). With higher economic growth, China has not been able to allocate more of its resources on health care than U.S.A. In 2008, the percent of GDP spent on health care by China was very low accounting for $4.3 \%$ of GDP, whereas U.S.A having the highest in the world spends much higher than China, about $16 \%$ of GDP on health care. THE of U.S.A as proportion of GDP had increased by approximately $2 \%$ from $14.1 \%$ in 2001 , whereas THE of China as the share of GDP had decreased slightly but hovered around $4.3 \%-4.7 \%$ over the decade. Within eight years (2000-2008) China's total spending on health has increased by almost 190\%, much higher when compared to U.S.A , which has increased by $73 \%$ in the same period. High GDP share of THE in U.S.A also corresponds with the higher per capita total expenditure in health. Compared to China, U.S.A per capita total health spending in terms of purchasing power parities (PPP) in 2008 was considerably higher amounting to $\$ 7,536$, the highest in the world, which was approximately about 30 times higher than China. Over the period from 2000 to 2008, China's per capita total health expenditure in terms of purchasing power parity (PPP int.\$) has doubled, which in 2000 was 43 times lower than U.S.A.

The similarity between the health financing system of these two countries was the private entity acting as higher source of revenue collection. U.S.A's expensive health system was mostly supported by private sector which accounts for $8.5 \%$ of the GDP share, 6\% higher than China's $2.5 \%$ GDP share. However the percentage contribution of private sector towards total health spending was similar in both countries accounting for $53 \%$ of THE in 2008. But the difference existed among these nations in the component of private funding source. Most of the private financing in U.S.A was generated from private health insurance which was relatively insignificant in China as source of financing. Out of pocket payment was the main component of private health care financing in China and accounted for $92 \%$ of private financing and $49 \%$ of total health care financing; private insurance shared only about $7 \%$ in 2008 . In contrast, out-of -pocket accounted for only $22.6 \%$ of private financing and $12 \%$ of total health care financing, whereby approximately $64 \%$ of private financing came from private insurance which was $34.1 \%$ of total health expenditure. This indicates that the majority of people in China have to utilize their own financing source in order meet their health care cost compared to the people in U.S.A, where private insurance plays a much higher role to meet the cost.

Despite higher private investment, public funding has increased continuously in these countries and has a similar value to that in 2008. Public financing on health as share of total health expenditure of China has increased from $38.7 \%$ (2000) to $46.7 \%$ (2008), reflecting the higher growth rate than U.S.A's $43.2 \%$ (2000) to $46.5 \%$ (2008). In contrary to the reasonable increase in government spending on health in China, it shares only about $2 \%$ of the GDP and less than $10 \%$ of the general government expenditure whereas in U.S.A its share is about $7.4 \%$ of GDP- about $5 \%$ greater than that of China, and more than $19 \%$ of general government expenditure. Less government spending in health sector in China was also highlighted by the lower level of the per capita government expenditure on health (PPP int. \$). Per- capita government spending on health in U.S.A amounted to $\$ 3,506$ in terms of PPP (2008), excessively higher (29 
times) than $\$ 121$ of China (2008). Almost

\begin{tabular}{|c|c|c|c|}
\hline \multicolumn{4}{|l|}{ HEALTH STATUS } \\
\hline Key Health Indicator. & Year & U.S.A & China \\
\hline Birth per 1,000 population. & 2010 & 14 & 12 \\
\hline Death per 1,000 population. & 2010 & 8 & 7 \\
\hline Rate of natural increase \% & 2010 & 0.6 & 0.5 \\
\hline \multicolumn{4}{|l|}{$\begin{array}{l}\text { Life expectancy at birth } \\
\text { (years) }\end{array}$} \\
\hline Total & 2008 & 78 & 74 \\
\hline Male & & 76 & 72 \\
\hline Female & & 81 & 76 \\
\hline
\end{tabular}

Healthy life expectancy (hale)

at birth (years)

2007

\begin{tabular}{|c|c|c|}
\hline Total & 70 & 66 \\
\hline Male & 68 & 65 \\
\hline Female & 72 & 68 \\
\hline
\end{tabular}

Neonatal mortality rate $\quad 2008 \quad 4 \quad 11$

Infant mortality rate $\quad 2008$

Total

7

18

Male

$\begin{array}{ll}7 & 15\end{array}$

Female

6

21

Under-5 mortality rate $\quad 2008$

Total

Male

$8 \quad 21$

Female

$9 \quad 18$

$7 \quad 24$

Adult mortality rate

Total

$2008 \quad 107 \quad 113$

Male

$135 \quad 140$

Female

79

84

Country reported estimates $\quad 2000-\quad 13 \quad 34$ of Maternal mortality ratio 2009 (per 100,000 live birth)
$54 \%$ of government funding on health was accrued from social security in China, which in U.S.A accounts about $27 \%$ in 2008 . The financing share of social security as a proportion of public expenditure on health has decreased in both countries. External resources do not represent the major sources of health funding in these countries.

Overall U.S.A appears to be better in most of the health outcomes in comparison to China as shown in table 4. In 2010, annual birth rate, death rate and rate of natural increase were similar in both countries, with China marginally lower than U.S.A. With the adaptation of one child policy, the total fertility rate of China has fallen to 1.5 children per woman, lower than U.S.A fertility rate of 2 children per woman. People born in U.S.A, male and female, live longer and healthier life and can survive, on average, four years more than people born in China. Also in both countries, females have a longer and healthier life expectancy at birth than males. Average life expectancy of an American citizen at birth was 78 years(2008)and healthy life expectancy at birth was 70 years (2007), and average life expectancy at birth and healthy life expectancy at birth were 74 (2008) and 66 (2007)years respectively for the Chinese population. The disparity of life expectancy at birth between male to female was similar in China and U.S.A. Child born in U.S.A enjoys the much safer life with less prevalence of dying before celebrating their $5^{\text {th }}$ birthday than a child born in China. Infant mortality rate, under-5 mortality and neo-natal mortality rate of both male and female were considerably lower in U.S.A than China. In 2008, under- 5 mortality rate and infant mortality rate of China were 21 and 18 respectively, more than double of U.S.A with under- 5 mortality rate and infant mortality rate of 8 and 7 respectively. The disparity 
between male to female was higher in China than U.S.A with female having higher prevalence of dying than male before celebrating their $5^{\text {th }}$ birthday. In contrast, the infant mortality rate and under-5 mortality rate for male in U.S.A was slightly higher than female. Adult mortality rate in both countries were very high, China comparably higher than U.S.A in both male and female, accounting average rate of 113 per 1000 population compared to 107 per 1000 population of U.S.A in 2008. Also the disparity between male and female exists, with female having lower rate than male in both countries. The estimated maternal mortality ratio for China during 2000-2009 was about 34 women per 100,000 births which was more than 2 fold higher than U.S.A. It indicates that the complications during pregnancy and child birth leading to death and disability among women of reproductive age are higher in China compared to that in U.S.A.

\section{DISCUSSION}

China, with its vast economic reforms , rapid industrialization and urbanization, on one hand faces challenges of health equity, inadequate health financing, high level of outof-pocket payment, cost escalation , inefficient use of scarce resources and disparities in health provision, whereas, on the other hand, strong economic growth, fiscal position and huge financial reserve have a high potential for substantial increase in the level of health financing, to accelerate protection from financial risks, to reduce burden of health cost and to achieve universal coverage [19]. Study suggests that there will be an increase in health expense as the country becomes wealthier [24]. In high income countries health expenditure growth and government health expenditure growth are faster than the growth of GDP, while outof-pocket payment (OOP) grows at around the same rate as GDP [25]. Similar trend has been observed in our result. With economic reform, rapid industrialization and urbanization, China is quickly marching towards the region of developed country. China's GDP growth rate is the highest in the world averaging $9.6 \%$ per year, and growth rate of health expenditure has already overtaken the GDP growth rate. Along with growth in total health expenditure, growth rate of general government expenditure on health has also increased sharply and has surpassed GDP growth rate.

Relative to country's wealth, China channeled low level of resources to health. Its total health expenditure as a proportion of the GDP and low per capita spending on health still remains less than other OECD countries and far below from other strong economic country like U.S.A [26].

During 1980's economic reform, health institutions were redefined as economic bodies rather than welfare entities [5]. Government has the ownership of Majority of health care facilities but for financial survival they rely on revenue generating activities, hence these facilities are termed as "private, for- profit" in terms of behavior [7]. Health didn't become the priority for the central government's agenda; hence government health budget was reduced. Regional disparities were exacerbated by the central government's tax sharing which favor the developed economic region and transfer policies favoring wealthier urban resident [27]. Thus poor localities had to pay from their own source for access to fewer and lower quality services. Central government 
was less concerned about the health sector and shifted the responsibility towards local government without sufficient funding, which created unfunded mandates in impoverished areas, leading to vast inequalities [28].

This in turn attributed to high share of private and low share of public funding on total health expenditure for more than a decade. Our study suggests that private health expenditure has dominated the health financing in China contributing more than $50 \%$ of THE, and sharing the higher proportion of GDP than that of GGHE. Further, majority of private health expenditure, more than $90 \%$ PvtHE or nearly $50 \%$ of THE, is dominated by the share of high individual out- of- pocket payment. Together, high outof- pocket payment and decline in the Government's contribution is partly a result of rapidly escalating health care costs and the lack of incentive for cost or quality control in the health delivery system [28]. Some of the contributing factors behind high cost and health inequality were inadequate government funding, and weak supervision and administration of health sector by government [11]. Countries with a high share of out-of-pocket payments are more likely to have a high proportion of households facing catastrophic health expenditure [29] and in China a study between 1998 and 2003 reveals that average rate of catastrophic medical spending increases, and credit entirely goes to rural areas where poorest rural group was the hardest hit [30].

We also observe that in recent years, trend in China's health financing is just opposite than what they were before. Government is more committed towards health care and health becomes the prioritized agenda for central government. With government focus on universal coverage of health insurance, the share of GGHE on total health expenditure and GDP has increased continuously. However, less than $10 \%$ total government expenditure on health in 2008 was even far less than the Abuja declaration (2001), made by the African Union, which endorsed at least $15 \%$ of total government expenditure to be allocated to health care [31].

Private expenditure started to decline and most of it coming from the reduction of out of pocket payment, which once in 2000 shared about $2.7 \%$ of GDP have decline to $2.1 \%$ of GDP in 2008. Study explains expansion of coverage by rural and urban insurance schemes were reasons behind the reduction of out- of- pocket payment in China [32]. We observe that private health insurance started to flourish in China by increasing their share towards health financing and this may be other additional factor.

With the collapse of the old commune-based rural cooperative in the 1980s, and during the introductory phase of URBMI and NRCMS in mid-to-late 2000s the majority of the Chinese population lacked health insurance coverage [33]. Holding the responsibility to protect citizen from catastrophic health expenditure and universal access to health services, government of China has introduced health system reform in 2009 [7]. Rapid progress has been observed in the health insurance coverage after the health system reform. The three health insurance scheme viz. the new rural cooperative medical scheme (NRCMS), the urban employee-based basic medical insurance scheme (UEBMI) and the urban resident-based basic medical insurance scheme (URBMI) are approaching the universal coverage. Basically Government subsidies and low premium for voluntary 
participant of NRCMS and URBMI and mandatory participation of UEBMI seem to be the reason behind the rapid coverage. Payroll contribution by employers and employee for UEBMI and subsidies by government for other scheme are expected to relieve the excessive financial burden of health care. Other factor may have the influence on health insurance coverage but we lack research. However, study on rural house hold found that financial protection from NRCMS was limited and health payment induced poverty on rural household after reimbursement did not drop much when compared to that before reimbursement [34]. Although we observe the rapid expansion of health insurance coverage but the coverage in terms of service benefit package and the financial protection provided is very small and limited [19]. In addition, fee for service payment system have increased burden on consumer because this system has created the overuse of health care services and also government administered price setting process which rules out bilateral negotiation between the government and providers has further exacerbated the problems. [35]. As well as the risk pooling is limited to municipality and county level. Hence access of poor people towards health service has not improved much and financial protection against high health cost and expensive health service remains restricted [19].

Finally the study of specific comparison with U.S.A illuminates the situation and level of health financing and health outcomes of China. In terms of health expenditure and health financing U.S.A outperforms China. China differs highly from the U.S.A in health expenditure and financing because of low level of resources allocated to health care. Huge difference in the share of total health expenditure to GDP and per capita total health spending explains China's low level of health financing and less commitment on the health care. As WHO report claims health expenditure reflects the government as well as household capacity and willingness to spend on health. Viewed as a share of GDP, total national health expenditure reflects the importance of health care in the overall economy [25]. This is also supported by lower share of total government spending on health care. Both systems rely on mix funding source and higher involvement of private entities for financing health care is common in both countries. In U.S.A private insurance is crucial factor for private investment where as in China individuals pay the price for health care. Comparatively high out- of- pocket payment share to private expenditure in China indicates that people are less protected from financial risk while seeking the health care and negligible role of private insurance. Although government spending on health is less, a large number of individuals in China have the social health insurance.

Corresponding to the high expenditure, U.S.A also shows better performance on most of the indicators of health outcome than China. High mortality rate including neonatal, infant, under -5 mortality rate and adult mortality, low life expectancy at birth, low healthy life expectancy at birth and high level of maternal mortality ratio are the reason behind low level of health outcome in China. Study shows health related disparities and inequities are the causes behind the low level of health outcomes in China, which in turn are the results of inadequate government spending, increased out-of-pocket health care cost, and unfair distribution of wealth and health services [36]. Apart from this, infectious diseases were also identified as the 
main cause for the higher mortality rate and lower life expectancy in China [37].

\section{CONCLUSION}

China is home of nearly 1.3 billion population. To provide quality and effective health service without catastrophic health expenditure for huge population is a strong challenge for the government. Low level of public funding and heavy reliance on out-ofpocket payment were the major problem in the past decades. In addition, people without insurance coverage were unable to pay the heavy cost of health service and those who had were also bound by the limited benefit. Limited role of private insurance and risk pooling limited to local or regional level were also the barriers for the financial protection. Hence the daunting problem of inadequate health financing ruled the last three decade of China health system.

Acknowledging the problem of the past three decades, the government has taken a significant step towards improving the health system. The government has already allocated a huge amount on health care with the view to improve the performance of health system. Achievement of the goal set by the new health system reform will be highly affected by the amount of public financing. Hence, we believe that expansion of public financing is required to achieve the universal access of quality health care in an affordable price for the entire population of China.

\section{REFERENCES}

1. Tang S, Meng Q, Chen L, et al. Tackling the challenges to health equity in China. Lancet 2008; published online Oct 20. DOI: 10.1016/S0140-6736(08)61364-1.

2. Gao J, Tang S, Tolhurst R, Rao K. Changing access to health services in urban China: implications for equity. Health Policy Plan 2001; 16: 302-12.

3. Trevor J.B, Dummer Ian G. Cook. Health in China and India: A cross-country comparison in a context of rapid globalization. Social Science \& Medicine 2008; 67: 590-605.

4. Ministry of Health. China's Health Statistics Yearbook. Beijing: China Union Medical University Press, 2007.

5. Liu X, Mills A. Financing reforms of public health services in China: lessons for other nations. Social Science \& Medicine 2002; 54:1691-1698.

6. World Bank. Rural health insurance - rising to the challenge. Rural Health in China: Briefing Note Series, note 6, World Bank, 2005.

7. Yip W, Hsiao W. China's health care reform: A tentative assessment; China Economic Review; Elsevier 2009; 20: 613-619.

8. International social security association. Chinese health-care reforms move towards universal coverage. ISSA, 2009. http://www.issa.int/NewsEvents/

News2/Chinese-health-care-reforms-movetowards-universal-coverage. (accessed February 20, Sunday 2011.)

9. Chinese State Council. Implementation plan for the recent priorities of the health care system reform (2009 - 2011) (published by the State Council, Beijing, 7 April). English translation as a reference only available on the Website of the National Development and Reform Commission, 2009. http://shs.ndrc.gov.cn/_ygjd/ygwj/ t20090408_271137.htm. (accessed February20, 2011.)

10. CPC; SC. Opinions of the CPC (the Communist Party of China) Central Committee and the State Council on deepening the health care system reform (Adopted by the State Council, Beijing, 23 January). English translation as a reference only available on the Website of the National Development and Reform Commission, 2009. http://shs.ndrc.gov.cn/ygjd/ygwi/ t2009040 8_2 7113 8.htm. (accessed February 20, 2011.)

11. Wang $\mathrm{H}, \mathrm{Xu} \mathrm{T}, \mathrm{Xu}$ J. Factors Contributing to High Costs and Inequality in China's Health Care System. Journal of American Medical Association 2007; 298(16): 1928-1930.

12. World Health Organization (WHO). Monitoring The Building Blocks of Health System: A 
handbook of indicators and their measurements strategies. WHO, Geneva, Switzerland, 2010.

13. OECD. Health update. The newsletter on health-related activities at the OECD. No.7-July 2009. Health account in the Asia - Pacific region: China, 2009. http://www.oecd.org/dataoecd/63/18/4330 5158.pdf(accessed February 18, 2011)

14. National Development and Reform Commission. Implementation Plan for the Recent Priorities of the Health Care System Reform (2009- 2011), 2009.

1. http://shs.ndrc.gov.cn/ygjd/ygwj/t20090408 _271137.htm (accessed February 24, 2011.)

15. Guo B. Transforming China's Urban HealthCare System. Asian Survey, University of California Press 2003; 43(2):385-403. In Adrien Dumoulin-Smith. Social Health Insurance in China: An Example of Nascent Social Security in China.http://inequality.cornell.edu/people/Pa persAbstracts/Dumoulin\%20 Smith_paper.pdf (accessed March 2,2011)

16. Dumoulin-Smith A. Social Health Insurance in China. An Example of Nascent Social Security in China. (date unknown). http://inequality.cornell.edu/people/ PapersAbstracts/Dumoulin\%20Smith_pape r.pdf (accessed March 11, 2011.)

17. Lei $X$, Lin $W$. The New Cooperative Medical Scheme in Rural China: Does More Coverage Mean More Service and Better Health? Health Economics 2009; 18: s25-s46. http://onlinelibrary.wiley.com/doi/10.1002/ hec.1501/abstract. (Accessed February 29, 2011)

18. Meng Q, Tang S. Universal coverage of health care in China: challenges and opportunity: World Health Report 2010, background papers no 7. World health Organization, 2010.

19. Hu S, Tang S, Liu Y, et al. Reform of how health care is paid for in China: challenges and opportunities. Lancet 2008; published online October 20, 2008. DOI:10.1016/S01406736(08)61368-9.

20. World Bank. The path to integrated insurance systems in China. China Health Policy, Notes 3 June 2010. World Bank, 2010.

21. Ney S. Unraveling the Global Health Crisis: Comparing Health Systems of 15 Countries, IIASA Working Paper, IIASA, 2008. https://www.appam.org/conferences/interna tional/singapore2009/sessions/downloads/1 501.pdf. (accessed 19 December 2010).

22. Cutner H. Farmers in China receive a bump in health care coverage. Live Insurance News; Posted March 13, 2011.http://www.liveinsurancenews.com/far mers-in-China-recieve-a-bump-in-health-carecoverage/852057/( accessed April 2, 2011).

23. ISSA( International Social Security Association) People's Republic of China. Crisis country case study. International Social Security Association. Geneva, 2010.

24. Musgrove P, Zeramdini R, Carrin G. Basic patterns in national health expenditure. Bull World Health Organ 2002; 80(2):134-42.

25. Xu K, Saksena P, Jowett M, et al. Exploring the thresholds of health expenditure for protection against financial risk. World Health Report (2010), Background Paper No 19. World Health Organization, 2010.

26. OECDiLibrary. Health at a glance. Health expenditure and financing. OECD Indicators, 2009. http://www.oecdilibrary.org/sites/health glance-2009-en/07/ index. html? contentType $=$ \&itemId $=/$ content $/$ chapter $/$ heal th_glance-2009-68-en\&containerItemId=/ content/serial/19991312\&accessItemIds =/content/ book/health_glance-2009en\&mime Type=text/html. (accessed 18 February, 2011.)

27. Hsiao, W. C. Disparity in health: the underbelly of China's economic development. Harvard China Review 2004; 5(1): 64-70.

28. World Health Organization, Western Pacific Region. Health system China, World Health Organization, 2008. http://www.wpro.who.int/countries/2008/ch $\underline{n}$ /national_heal th_priorities.htm. (accessed December 22, 2011).

29. Tangcharoensathien $\mathrm{V}$, Patcharanarumol W, Ir $P$, et al. Health-financing reforms in southeast Asia: challenges in achieving universal coverage. Lancet, 2011; published online Jan 25. DOI:10.1016/S0140-6736(10)61890-9.

30. Liu Y, Rao K, Wu J, Gakidou E. China's health system performance. Lancet, 2008; published online Oct 20. DOI: 10.1016/SO1406736(08)61362-8.

31. Abuja declaration on HIV/AIDS, tuberculosis and other related infectious diseases. African Summit on HIV/AIDS, tuberculosis and other related infectious diseases, Abuja, 2001. 
http://www.un.org/ga/aids/pdf/abujadeclara tion.pdf (accessed March 3, 2011).

32. World Health Organization. Health Financing Strategy for the Asia Pacific Region (20102015). World Health Organization, 2009.

33. Wagstaff A, Lindelow M, Wang S, Zhang S. Reforming China's Rural Health System. The World Bank, 2009.

34. Sun X, Sleigh AC, Carmichael GA, Jackson S. Health payment-induced poverty under China's New Cooperative Medical Scheme in rural Shandong. Health Policy Plan 2010, 25(5): 419-426. Published online March 22, 2010.

35. Ma S, Sood N. A comparison of the health system in China and India. Central for Asia Pacific Policy, RAND Corporation, 2008.

36. The Lancet. China faces daunting challeges to heatlh equity but it has the means to turn these problems around. The lancet press release, 20 October, 2008.

37. The Lancet. China's early detection system for infectious diseases could be vital in warning world of bird-flu pandemic. The lancet press release, 20 October, 2008.

\section{DATA SOURCES}

1. WHO. World Health Statistics 2010. Geneva, Switzerland; World Health Organization, 2010.

2. WHO. World Health Statistics 2010: Indicator compendium Interim version. Geneva, Switzerland, World Health Organization, 2010.

3. PRB. 2010 World Population Data Sheet; Population Reference Bureau, 2010. http://www.prb.org/pdf10/10wpds_eng.pdf; (accessed 15 January 2011).

4. WHO. National Health Account: China; World Health Organization, 2011. http://www.who.int/nha/country/chn.pdf. (accessed February 6, 2011).

5. WHO. National Health Account: China; World Health Organization, 2011. http://www.who.int/nha/country/usa.pdf (accessed February 6, 2011)

6. Sussmuth-Dychkerhoff C, Wang J. China's health reform; Health International, 2010. No 10. http://www.mckinsey.com/clientservice/ payorprovider/ pdfs/issue10/HI10_China_healthcare_reform. pdf(accessed March 3, 2011). 